\title{
Esperança e possibilidade em Ernst Bloch
}

\section{Hope and possibility in Ernst Bloch}

Mariana Carvalho'
Data de submissão: 21-07-2014

Data de aprovação: 25-07-2014

1 Graduada em Ciências Sociais na Universidade Federal da Bahia. Email: carvalhop.mariana@ gmail.com.

\section{Resumo}

Este artigo propõe esboçar algumas ideias sobre o conceito de esperança em Ernst Bloch, diferenciando-o do seu uso corrente pela tradição platônico-cristã. Para Bloch, a esperança (longe de ser um afeto passivo) é inerente à própria estrutura histórica e biológica do homem, constituindo uma margem contínua de possibilidade do presente, a partir da qual é possível uma verdadeira crítica deste. Ao defender a esperança como práxis diária, Bloch resgata o sentido positivo da utopia contra os detratores do sonho, distribuídos nas fileiras do niilismo e do pessimismo. Ademais, este artigo propõe uma contraposição entre o conceito de esperança em Bloch a partir de dois interlocutores privilegiados: Walter Benjamin e Peter Sloterdijk. O primeiro entendendo a esperança a partir de um forte traço messiânico, conectando-a a uma interrupção da continuidade histórica que, em tese, prepararia terreno para uma revolução social; o segundo, como uma força acumulada junto aos desejos de vingança.

Palavras-chave: Esperança. Possibilidade. Materialismo Histórico. Bloch. Benjamin. Sloterdijk.

\section{Abstract}

This paper aims to outline some ideas about Ernst Bloch's concept of hope, contrasting with the usual meanings on christian-platonism's tradition. According to Bloch, the hope is inherent in the social structure and biological of men, it makes a continuous range of possibility that enables a true criticism of present. Bloch defend the idea of hope like a daily praxis, and rescues the positive meaning of utopia against the dream's detractors spread on the rows of nihilism and pessimism. Furthermore, this paper distinguishes Bloch's concept of hope from Walter Benjamin and Peter Sloterdijk, two remarkable interlocutors. Benjamin understands hope from a strong messianic bond, connecting it with some kind of gap of historical continuum that, theoretically, would set the stage to social revolution. Sloterdijk think on it as a force loaded with desires for vengeance.

Keywords: Hope. Possibility. Historical Materialism. Bloch. Benjamin. Sloterdijk. 
Em O Princípio Esperança, Ernst Bloch se propõe a resgatar o conceito de esperança da passividade pejorativa da tradição platônica e cristã, recuperando assim o sentido positivo da utopia e do sonho como portadores de uma vontade atuante, capaz de modificar a realidade mediante uma práxis de viés marxista ${ }^{2}$. Tal dinamismo pressupõe a convicção de que o processo do mundo ainda não está decidido ${ }^{3}$, e que este devir pode conferir concretude à esperança, se entendida como esforço construtor que leva em conta as contradições reais do presente. Tais contradições seriam os principais indícios do caráter contingente da realidade.

Sendo a esperança este olhar aberto fixamente adiante (no horizonte em formação), o prognóstico deve "retornar" ao presente trazendo a visualização das condições materiais objetivas para sua realização, evitando tanto reduzi-la a uma visão idealista do futuro quanto invertê-la ideologicamente como conformidade e resignação. Ao contrário, a esperança deve ser o que cede margens que possibilitam uma real crítica ao presente, uma régua de medição de suas possibilidades.

Porém, este tempo presente no qual os homens, de fato, vivem, sonham e trabalham, não é, de forma alguma, nem a constatação do fracasso das utopias, nem a reprodução contínua de suas decepções. Para Bloch, este discurso derrotista é construído, financiado, reproduzido e difundido pelos detentores do poder, que são, não por coincidência, os detratores de plantão do sonho, na medida em que se interessam pela manutenção de antigos privilégios adquiridos, os quais o cinismo, o niilismo e o derrotismo, em tese, manteriam - por cansaço, indiferença e generalização como norma ${ }^{4}$ (aqui entendida em sua função ideológica, por inversão mantenedora dos interesses classistas ${ }^{5}$ ).

De acordo com a análise do autor, a esperança

2 "O esperar e o esperado, no sujeito e no objeto, respectivamente, o fenômeno do emergir como um todo não suscitou, até Marx, nenhuma abordagem global em que encontrasse um lugar, quanto mais um lugar central”, (BLOCH, 2005, p. $16)$.

3 "O propriamente dito no ser humano como no mundo ainda está por acontecer", (BLOCH, 2005, p 243-244).

4 "O interesse burguês gostaria de arrastar para dentro do próprio fracasso justamente cada um dos demais interesses que lhe são contrapostos" (BLOCH, 2005, p. 15).

5 "Cada nova classe que assume o lugar da que dominava antes dela é obrigada, nem que só para alcançar seus fins, a representar seu interesse como o interesse comum de todos os membros da sociedade" (MARX; ENGELS, 2007, p. 77). resiste às provas do tempo justamente por ser inerente à própria estrutura biológica e histórica do homem ${ }^{6}$, tanto que se mostra presente nas manifestações humanas mais primárias (objeto da parte I de O Princípio Esperança), até as representações sofisticadas de sua maturidade clássica (objeto da parte II em diante). Sua inerência ao processo histórico humano a exime de, em sua forma atualizada, fazer julgamentos de valor que a comparem a utopias do passado. Uma esperança não deve fazer referência a outra anterior, o que anularia sua força e inflamaria os discursos teatrais do niilismo, que exigem que ela pague pelo privilégio de existir no presente, quando viver no presente é seu direito intrínseco.

A realidade atual não é o espaço da constatação dos fracassos utópicos, uma vez que nenhum fracasso é definitivo frente ao dinamismo das forças históricas. Esta ideia de movimento, em Bloch, é muito importante, na medida em que o posiciona a favor de um pensamento que defina a efetividade do real como processo, subjacente à superfície calma e aparentemente estanque do mundo ${ }^{7}$. Assim, enquanto o discurso dos vencedores aceita e defende a realidade como norma, a esperança só a aceita e a defende como espaço aberto, ainda em construção. Tal espaço aberto, em tese, abarcaria todas as possibilidades em suspenso.

Em suas teses sobre o conceito de história, Walter Benjamin (1985) amplia essa discussão ao afirmar que, se a historiografia é, de fato, a escrita positiva do discurso dos vencedores em detrimento do silêncio e da invisibilidade dos vencidos e dos mortos, cabe ao historiador utilizar o materialismo histórico para lançar mão da "tradição dos oprimidos", a qual "nos ensina que o 'estado de exceção' em que vivemos é na verdade a regra geral" (BLOCH, 2005 , p. 226). O que Benjamin chama aqui de "estado de exceção" é um vulto de contingência dentro da aparente normalidade do estado de direito. É na consciência dessa condição contingente da realidade que as energias positivas da esperança devem se localizar contra o fascismo, célebre portador dos discursos autoritários que visam a ini-

6 "O animal dirige-se para o alvo conforme lhe dita o apetite no momento, o ser humano o retrata por antecipação" (BLOCH, 2005, p. 50).

7 "Do lado de fora, porém, a vida é tão inconclusa como no eu que opera nesse lado de fora. Nenhum objeto poderia ser reelaborado conforme o desejo se o mundo estivesse encerrado, repleto de fatos fixos ou até consumados" $(\mathrm{BLOCH}$, 2005, p. 194). 
bir a passagem para sua realização concreta. A este novo posicionamento, Benjamin chama de "verdadeiro estado de exceção" (BLOCH, 2005, p. 226), o qual, longe de produzir qualquer tipo de legitimidade, produz uma situação de manutenção de poderes que ocupam um espaço vazio, ainda não preenchido por nenhuma outra possibilidade.

Nesse sentido, observamos tanto em Benjamin quanto em Bloch a mesma tática de movimentação das interpretações do passado até a fundamentação das narrativas do presente, as quais possuem duas vias: ou inibir ou validar os próximos passos em direção ao futuro. Ocorre que, para Benjamin, antes de nos dirigirmos ao futuro, precisamos nos livrar da ideia de progresso, e desenvolver uma verdadeira crítica (marxista e messiânica) que conecte a interrupção da continuidade histórica com o conceito de revolução social ${ }^{8}$.

Já Bloch (2005, p. 195) mantém a defesa do progresso, mas de um que esteja estreitamente ligado à ideia de processo de mudança, como novo paradigma qualitativo, e não linear e quantitativo, ou conformista; um progresso que dê conta do fato de que "a própria realidade ainda não foi elaborada, que ela contém em sua margem coisas que se avizinham, que estão irrompendo".

O cinismo produzido por um progresso vazio e homogêneo é só uma nova forma de envelhecer, contra a qual a esperança rejuvenesce. A imagem do espaço aberto no lugar do espaço da constatação cínica aponta para o fato de a espera otimista não servir apenas para medir nossa fraqueza presente. Esta é tese spinozista, segundo a qual quanto maior minha potência atual menor minha necessidade em esperar ${ }^{9}$. Porém, o espaço aberto assinala da esperança sua vontade ativa, isto é, seu desejo em deslocar nossa potência para outros fins a princípio não imediatos.

8 "A ideia de um progresso da humanidade na história é inseparável da ideia de sua marcha no interior de um tempo vazio e homogêneo. A crítica da ideia de progresso tem como pressuposto a crítica da ideia dessa marcha". (BENJAMIN, 1985, p. 229).

9 Ao final da parte III da Ética há as definições dos afetos, como desenvolvimento da proposição 59, onde Spinoza define na décima segunda seção, a esperança como uma "alegria instável, surgida da ideia de uma coisa futura ou passada, de cuja realização temos alguma dúvida”. Em seguida, o filósofo define o medo, em termos contrários, como tristeza, e conclui não haver "esperança sem medo, nem medo sem esperança" (SPINOZA, 2007, p. 95). Tal instabilidade da alegria da esperança estaria ligada à dúvida. Retirada a dúvida, a esperança se torna segurança. Para Spinoza, nossa dúvida será cada vez menor quanto maior nosso grau de potência para concretizar nossos desejos.
Ademais, se a temporalidade de fato transforma desejo em esperança, de modo algum é em detrimento do desfrute de sua potência atual. Pelo contrário, soma-se a esse desfrute um horizonte de expectativas frutíferas. Bloch (2005, p. 195):

O que não é ainda pode vir a ser; o que é realizado pressupõe coisas possíveis na sua matéria. Há, no homem, esse elemento aberto, e ele é habitado por sonhos, planos. O elemento aberto existe igualmente nas coisas, na sua extremidade mais avançada, onde o devir ainda é possível.

O filósofo Peter Sloterdijk (2012) coloca em termos mais enérgicos e menos naturalizados tanto a questão do horizonte propiciado pelo devir nunca decidido quanto do deslocamento das potências transformadoras atuais, diferindo sua ideia de esperança da de Bloch e Benjamin. Para ele, existiria um "banco mundial da ira" (fundado pela teologia monoteísta e depois "comprado" pelos movimentos revolucionários de viés marxista) no qual, em tese, os vencidos da história "investem" sua esperança, enquanto aguardam o momento certo da reviravolta dos processos históricos. Tal reviravolta, segundo o autor, não se dará por outro meio que não a violência (identificada pelo filósofo com o terrorismo): "os habitantes das nações abastadas perambulam na maioria das vezes como sonâmbulos num pacifismo apolítico. Passam seus dias numa insatisfação dourada. Entretanto, nas margens das zonas de felicidade, aqueles que os incomodam, sim, os seus carrascos virtuais, aprofundam-se em manuais de químicas de explosivos, emprestados das bibliotecas públicas dos países anfitriões".

Desse modo, na visão irreverente e apocalíptica de Sloterdijk, a esperança seria alimentada constantemente pela ira, pelo ressentimento, e acumulada junto aos desejos de vingança, funcionando como válvula de escape ou linha de crédito cuja função é a de prorrogar desejos não realizados, no intuito de manter, por ora, o equilíbrio político. Nesse sentido, podemos dizer que Sloterdijk trata da esperança em termos spinozistas, isto é, medida conforme graus de potência atualizados, ainda que sua análise venha a reboque do estudo da presença da "ira" no pensamento ocidental, sobretudo a partir das tragédias gregas. Para Sloterdijk a ira sempre foi um sentimento encarado como positivo nas sociedades guerreiras e heroicas, até ser substituída pelo conceito de justiça, que colocou a ira ao lado da esperança, como "ativos bancá- 
rios" nas grandes "poupanças" do futuro ${ }^{10}$.

Porém, se o espaço aberto, ainda não explorado, pode tanto ser utilizado pelo messianismo (em Benjamin) quanto por uma esperança rancorosa e vingativa (em Sloterdijk), é o materialismo dialético, para Bloch, quem inscreve o espaço aberto como princípio natural, de acordo com o conceito de uma natureza definida segundo a fórmula aristotélica de movimento e repouso, ou, como diz o próprio Bloch (2005, p. 18), "no conceito abrangente da matéria aristotélica como possibilidade para a essência”. Em outras palavras, as infinitas variações da matéria finita promovem um movimento ascendente no qual tudo aquilo que se encontra latente, sedimentado no real como possibilidade, tenha sua chance de ascender à existência, passando do possível para o fato dado. Tal naturalização desembaraça o conceito de esperança em Bloch de qualquer resquício de rancor ou caráter messiânico.

Assim, neste cenário no qual o mundo está em constante devir e onde não se encontram pontos de apoio na natureza que flui (e não permanece), qualquer ponto que se tome do espaço infinito pode ser um começo e uma direção. Este relativismo é extremamente positivo para a esperança, se a entendermos como um esforço seletivo, o qual deve manter sua força de convencimento mediante um estudo mais aprofundado da realidade atual que aponte a mais forte tendência do futuro.

Esta tendência é a possibilidade. Seu conceito confere mais movimento ao de esperança, inserindo-a como parte do processo histórico do mundo ${ }^{11}$. Mas, em que consiste a possibilidade? Bloch (2005, p. 195) responde que, como:

o propriamente dito no ser humano e no mundo ainda está para acontecer, está na expectativa, encontra-se sob o medo de ser frustrado, na esperança de ser bem-sucedido [...] aquilo que é possível pode tanto se tornar um nada quanto um ser: um possível, não sendo totalmente condicionado, é o não-consumado.

De acordo com esta leitura, a possibilidade não estaria fora do acontecimento real, mas, potencializada na

$10 \mathrm{Na}$ entrada de cada um desses bancos da ira e da esperança, há uma inscrição com a célebre frase atribuída a Agostinho de Hipona: "a esperança tem duas filhas lindas, a indignação e a coragem".

11 "O fator objetivo é a potencialidade não encerrada da mutabilidade, da alterabilidade do mundo no quadro de suas leis, de suas leis que, no entanto, também podem variar regularmente sob novas condições" (BLOCH, 2005, p. 245). expectativa de sua eclosão em um dado tempo e lugar. Em outras palavras, tudo aquilo que "é" caminha ao lado do que "pode ser". O problema é que nosso raciocínio ontológico costuma valorizar o fenômeno dado imediatamente em detrimento do ainda não dado, de modo a considerar que só o que existe tenha valor, pois seu valor é sua própria distinção como existente. Já o possível é mais difuso, mais passível de erros, mais "malsucedido", uma vez que, se fosse bem-sucedido, existiria de fato.

Como Bloch resolve esta questão? Mediante a ideia de que "o possível, não sendo totalmente condicionado, é o não-consumado". Condicionado pelo quê? Pela contradição $o^{12}$. Desse modo, não sendo contraditório que o possível exista, ele só não existiu ainda por não ter sido consumado, já que sua existência não é contraditória quando comparada a circunstâncias similares, algumas das quais geraram um dado do acontecimento enquanto outras não. A força da possibilidade estaria em ela não querer ser circunstância, mas acontecimento, pois todo possível exige existir. Esta “exigência” é a própria esperança, que em Bloch aponta para uma pendência do real que, ao existir de modo "imperfeito", traiu suas próprias potencialidades.

Aqui o conceito de possibilidade em Bloch difere daquele pensado, em sua forma clássica, por Leibniz (1979). Para este, a realidade é a realização da melhor possibilidade, da mais perfeita e bem acabada forma do possível, em detrimento das outras tendências que não vingaram que não se realizaram por não exprimirem $o$ melhor possível. Desse modo, a própria constatação do real como existente bastaria para comprovar sua eficiência e perfectibilidade.

Esta ideia é estranha a Bloch. Para ele, a possibilidade realizada não é provável por si mesma, antes é uma realidade formal, resultado patente do embate entre relações materiais de forças produtivas, mas nem por isso isenta de imperfeições, através das quais o possível busca se reconciliar, por irresistível magnetismo, com os polos de uma nova realidade. Nesse sentido, o real é sempre contingente $^{13}$ em Bloch, pois constantemente ameaçado

12 Contradição não apenas lógico-formal, mas entendida como prova de necessidades reais e critério para a existência do real.

13 Em Bloch, todo último "fato" é sério "candidato" a se tornar o primeiro de uma nova série, e não um capítulo final, desde que sempre de acordo, neste ponto, com a contingência em Leibniz, que é a distinção esquemática entre possibilidade ou impossibilidade lógica. 
pelos assaltos dialéticos do possível não-contraditório.

A possibilidade torna o real intermediário. Imaginemos então (com Bloch) a realidade como um navio costeado, castigado pelas ondas do devir. A costa na qual se ancora é a possibilidade. $\mathrm{O}$ marinheiro que vai à costa em missão de reconhecimento é a esperança. Que instrumentos de inspeção o marinheiro usa para reconhecer terreno? O materialismo histórico: "sendo o tempo, de acordo com Marx, o espaço da história, então o modo futuro do tempo é o espaço das possibilidades reais da história" (BLOCH, 2005, p. 244).

O materialismo histórico depura a esperança, evitando sua queda no idealismo ou nas religiões que substituem Deus pelo futuro. Sem o método materialista, a ideia da possibilidade como realidade preexistente fatalmente incorre nestes erros de inversão platônica, tanto que não podemos crer como coincidência o fato de a maioria dos socialistas utópicos (a exemplo de Fourier e Saint-Simon) ter sido formada por homens religiosos, de modo que o primeiro esforço de Engels (2010) se direcionou no sentido de separar o socialismo utópico do científico, colocando este último em um terreno real, de cuja análise partiria as soluções reais capazes de transformar a realidade.

Após Engels e Marx, a esperança socialista não pode mais se resumir a idealizar o futuro, sonhando com um sistema social o mais perfeito possível, mas em estudar o desenvolvimento histórico e econômico que culminou na realidade presente, criando os meios para resolver seus conflitos. Não se trata mais, portanto, de sonhar com o futuro, mas de conhecê-lo cientificamente a partir das tendências (logo, das possibilidades) delineadas no agora.

A imagem alegórica do anjo da história utilizada por Benjamin (1985, p. 226) ilustra bem essa ideia. Das ruínas de onde vislumbra uma sucessão de catástrofes, o anjo, impelido pela tempestade que é o progresso, aponta para tudo aquilo que não foi, mas que poderia ter sido e ainda pode ser, desde que não se permita que a marcha da história silencie as tendências que fugiram de seus elos por não se adequarem à sua cadeia de eventos. $\mathrm{O}$ anjo benjaminiano nos convida a despertar as possibilidades que não vingaram, as quais podem tanto alterar o presente quanto o passado e o futuro. Mas esse movimento só é possível se entendermos a história como "objeto de uma construção cujo lugar não é o tempo homogêneo e vazio, mas um tempo saturado de 'agoras", o qual se deve fazer "explodir do continuum da história" (BENJAMIN, 1985, p. 229).

Podemos intuir duas ideias a partir da defesa do materialismo histórico impetrada por Bloch. A primeira é a de que a possibilidade é uma força enriquecida pela experiência, e não contradita por ela. A segunda é a de que a possibilidade é um espelho diante do qual o real se torna mais real, despertando as forças de sua própria regeneração ${ }^{14}$. A primeira ideia defende o conceito de esperança em Bloch de qualquer idealismo platônico-cristão; a segunda, da ingenuidade ontológica que entende o máximo de valor como o máximo de ser.

A esperança não tem outro direito senão sua força de se tornar realidade. Esta força é medida pela potência que tem a possibilidade em querer existir. Porém, neste processo, o homem deve, necessariamente, impor sua vontade ativa. Se o mundo é um processo em construção no qual nada está acabado, não há quem possa antecipar sua experiência histórica, e, até que ela ocorra, tudo permanece no espaço do possível. É a vontade do homem que resgata o concreto desse possível aberto ${ }^{15}$.

Toda ação humana deve ser a contingência querendo se tornar necessária diante da possibilidade, até que a incerteza da esperança diminua diametralmente ao passo em que aumente a vontade de produzir essa certeza. Esta dialética reside no fato de a possibilidade requerer aquele raro ponto médio entre semelhança e diferença em relação à realidade. Para suplantar esta e se tornar efetivamente real, a possibilidade não pode subsistir de esperas isoladas. Ela não necessita de pretendentes messiânicos (como em Benjamin), nem de vingadores rancorosos (como em Sloterdijk), mas de construtores.

Esta imagem da realidade como um processo em construção, no qual tudo parece permanente até que o segredo de sua fragilidade seja revelado, aparenta trazer em si mesma a própria ideia de progresso, representada na prioridade das linhas horizontais (as da eficiência e eficácia) em direção ao futuro - quando todas as utopias cantarão e todos serão felizes. Este sentido teleológico deve ser bem conduzido, de modo a não resvalar em messia-

14 "Somente esta práxis pode transportar a causa pendente do processo histórico, a naturalização do homem, a humanização da natureza, da possibilidade real para a realidade" (BLOCH, 2005, p. 244).

15 "No entanto, como no caso do homem a capacidade ativa é parte especial da possibilidade, a utilização dessa atividade e valentia no momento e na medida em que ela ocorre, produz uma preponderância da esperança" (BLOCH, 2005, p. 244). 
nismos de classe ou dogmatismos platônicos que ameaçam transformar ciência em profecia. Aqui a possibilidade deve servir de contrapeso, aconselhando o comedimento e a análise fria ao acentuar tanto seu próprio caráter de tendência quanto o fato de a esperança sempre se encontrar na linha tênue entre exprimir mais seus limites que sua realidade.

Neste caso, não devemos abandonar a diferença entre juízos descritivos e juízos de valor, isto é, nenhuma descrição factual deve ser invocada como um valor absoluto contra a comunidade dos anseios legítimos por felicidade. E mais: não se deve legitimar a esperança afirmando que esta trará a felicidade por vir. Tivemos exemplos o bastante para perceber que os piores crimes da história (como os cometidos em nome do nazismo, estalinismo, dentre outros "ismos") foram cometidos sob este auspício. Antes, a esperança deve consistir em modificar os próprios parâmetros daquilo que, no presente, entende-se por felicidade.

Em Bloch, esta modificação atua no instante como a luz que, invisível, atravessa o espaço até incidir sobre um objeto e se tornar visível. Este “objeto" pode ser o momento em que a possibilidade nos surpreende fora do que nos é próprio, abrindo nossos olhos diante de potencialidades que até então desconhecíamos, pois ocultas sob os disfarces de uma impotência momentânea que se quer definitiva. Neste sentido, esperança e possibilidade, para Bloch, parecem caminhar menos para uma ideia de progresso e mais para a de uma atualização dos combates essenciais, os quais, aliados a uma vigília sobre a história e à construção de uma atenção sobre a legitimidade do real, manteriam o homem nos contornos de um sentido humano solidário, capaz de fazer frente à alienação normativa que adere ao presente por estupor, indiferença, e maquinismo ${ }^{16}$.

O que progride no progresso? Esta pergunta, que norteia toda a análise da Escola de Frankfurt, parece estar implícita (por exclusão) nos princípios de esperança e possibilidade blochiano, pois, ao modificar a natureza, o homem modifica a si mesmo enquanto parte da natureza, uma vez que não é - como queria Descartes- uma res cogitans separada do mundo e não influenciada por ele.

16 A esperança critica a noção de vida como adequação da realidade, não por reconhecer a força dos fatos, mas por entender que a rede de relações factuais não possui uma definição última.
O que modificou na essência do homem com o progresso? Ficamos mais solidários, mais voltados para o outro, mais tolerantes, mais honestos, menos alienados, menos egoístas, mais compassivos? Parece-nos que nos aproximarmos mais destas disposições humanas é o verdadeiro progresso para Bloch.

De resto, a quem interessa que não consigamos atingir este progresso? A quem interessa que nada mude (ou que a modificação ocorra no mesmo plano, evitando a ocorrência de uma radical mudança de plano), ou que nada de novo se introduza contra esta realidade "bem" estabelecida? O que está em jogo em Bloch não é a posse totalitária ou a fuga romântica de uma realidade dada, mas o estatuto que lhe reconhecemos. Para Bloch isto não é apenas um problema ontológico, mas prático, humano.

Para Walter Benjamin (1985, p. 230-231), tal problema só pode ser resolvido durante a luta contra o historicismo que quer negar o passado e, consequentemente, o presente, tornando-o estanque: “o materialista histórico não pode renunciar ao conceito de um presente que nao é transição, mas para no tempo e se imobiliza. Porque esse conceito define exatamente aquele presente em que ele mesmo escreve a história. O historicista apresenta a imagem 'eterna' do passado, faz desse passado uma experiência única".

A esperança, afinal, é a verdade imanente de um mundo em eterno devir, de modo que, se tudo tem uma causa e nada tem um sentido, este é (e será sempre) construído pela esperança, tanto como forma de aprendizado, quanto como um tom antecipador frente ao desconhecido. Não se trata de um procedimento puramente instrumental, mas de um modo de comparar a representação de uma realidade (de maneira alguma imutável) com a possibilidade de concretização de esperanças mais frutíferas.

Cada ação humana requer um motivo para dispender energia, e a consciência desse esforço será boa ou má conforme o motivo ser baixo ou elevado. Só a esperança eleva nossas ações, guiando-nos para atividades mais nobres. Só ela produz o movimento que faz a história, pois constitui a própria essência da luta, do desejo de mudança. A esperança é a própria constatação de que a realidade é inesgotável, multiforme, aberta, provisória daí constantemente necessitar de novos nortes, novas direções, novos construtores. Que a esperança nos seja essa exigência pura, norteadora. 


\section{Referências}

BENJAMIN, Walter. Obras escolhidas: magia e técnica, arte e política. 3 ed. São Paulo: Brasiliense, 1985.

BLOCH, Ernst. O princípio esperança. Rio de Janeiro: UERJ, 2005.

ENGELS, F. Do socialismo utópico ao socialismo científico. São Paulo: Edipro, 2010.

LEIBNIZ, G. W. Discurso de metafísica. São Paulo: Abril Cultural, 1979.

MARX, Karl; ENGELS, F. A ideologia alemã. São Paulo: Boitempo, 2007.

SLOTERDIJK, Peter. Ira e tempo. São Paulo: Estação Liberdade, 2012.

SPINOZA, B. Ética demonstrada à maneira dos gêometras. Belo Horizonte: Autêntica, 2007. 